\title{
An unusual cause of vomiting in a child
}

\author{
Mukta Mahajan, ${ }^{1}$ Vidhyachandra Gandhi, ${ }^{2}$ Aabha Nagral ${ }^{3}$ \\ ${ }^{1}$ Department of Radiodiagnosis, Jaslok Hospital and Research Centre, Mumbai, Maharashtra, India \\ 2Department of Gastrointestinal Surgery, Jaslok Hospital and Research Centre, Mumbai, Maharashtra, India \\ ${ }^{3}$ Department of Gastroenterology, Jaslok Hospital and Research Centre, Mumbai, Maharashtra, India
}

Correspondence to Aabha Nagral, aabhanagral@gmail.com

\section{Summary}

The authors report the case of a 13-month-old male child who presented with sudden onset vomiting and refusal to take solid food. Barium swallow and CT scan of the chest were inconclusive. The cause of symptoms was only evident more than a month later on endoscopy, which revealed an unusual flower-shaped foreign body impacted in the cervical oesophagus. This was successfully removed, and review of imaging made the diagnosis obvious in retrospect. This report is to emphasise the importance of considering the possibility of foreign body ingestion with unusual sudden onset symptoms and vigilant interpretation of findings on imaging studies, especially in the paediatric population.

\section{BACKGROUND}

Vomiting in a child can be due to a wide range of etiological factors. We report a child with a unique cause of vomiting.

\section{CASE PRESENTATION}

A 13-month-old male child presented with sudden onset of non-bilious vomiting following solid feeds, which lasted over a period of $1 \frac{1}{2}$ months. The child grew increasingly irritable and completely refused to eat solids. Severe vomiting would ensue on intake of the smallest bolus of softened solid food. There was no fever or respiratory symptoms. The child was a full-term normal delivery, with a birth weight of $2.1 \mathrm{~kg}$. His milestones and growth parameters were normal for his age and sex. The symptoms were attributed to teething. His symptoms persisted with a weight loss of $1 \mathrm{~kg}$ over a period of $1 \frac{1}{2}$ months and at this stage he was referred to our centre.

Prior to the referral, the child had a barium swallow examination, which showed hold-up of barium and a short segment stricture in the cervical oesophagus. The mucosa appeared smooth and regular. There was proximal dilatation with some filling defect within, which was interpreted as food residue above the level of the stricture (figure 1).

\section{INVESTIGATIONS}

CT scan of chest and neck was done to evaluate the nature of the lesion and to rule out an extrinsic pressure effect due to a probable double aortic arch. CT scan was reported as presence of 'stricture' in the cervical oesophagus with proximal outpouching, without any extrinsic compression (figure 2A,B).

\section{TREATMENT}

Keeping in mind the clinical background and imaging findings, the child was subjected to an upper gastrointestinal endoscopy (Olympus videoscope 160 series) under general anaesthesia (ketamine + midazolam) with endotracheal intubation to protect the airway. Oesophagoscopy showed an impacted plastic foreign body just below the cricopharynx, embedded deep within its two opposing walls (figure $3 \mathrm{~A})$. This was dislodged with the help of a rat toothed forceps and then once the entire foreign body was dislodged, it was caught with a polypectomy snare and pulled out of the oesophagus. This foreign body was found to be a flower-shaped object measuring $1.5 \times 1.5 \mathrm{~cm}$, with a central hole (figure 4). The foreign body was part of a garland put around a God's idol. On removal of the entire foreign body in one piece, the oesophageal mucosa showed deep mucosal ulcers and oedema at the site of the foreign body impaction (figure 3B). Following this, a water soluble gastrograffin swallow was done, which did not show any leak of contrast. The child was started on a liquid diet from the next day and was subsequently switched to a full diet, which he tolerated well.

\section{OUTCOME AND FOLLOW-UP}

He has gained $2 \mathrm{~kg}$ weight in the last seven months and remains asymptomatic on follow-up.

\section{DISCUSSION}

Foreign body ingestion is a common problem in the paediatric population. ${ }^{1}$ Serious complications from foreign body ingestion, including sudden death, oesophageal perforation and abscess formation have been reported. The nature of the foreign bodies, their presentation and management in the paediatric population differ from those of the adults. Patients with oesophageal foreign bodies require prompt diagnosis and therapy.

Ingested foreign bodies most commonly get impacted in areas of physiological narrowing like the cricopharyngeus muscle of the upper oesophageal sphincter, the aortic arch, the left mainstem bronchus and the lower oesophageal sphincter ${ }^{2}$ as was seen in our patient. Children often have typical symptoms but are more likely than adults to be asymptomatic, though they have an increased frequency of respiratory symptoms. Foreign body obstruction should 


\section{BMJ Case Reports}

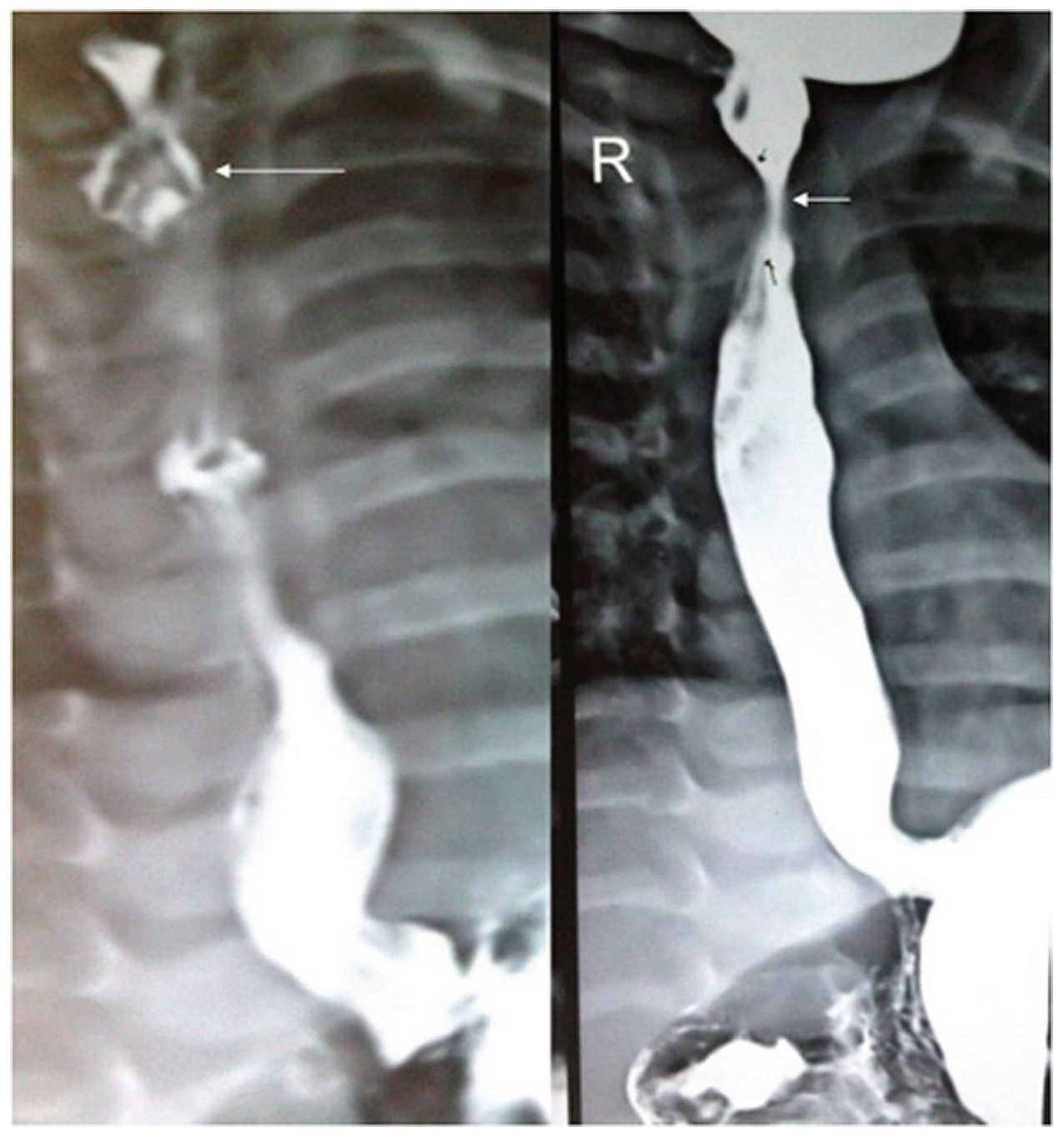

Figure 1 Barium swallow examination showing a smooth short segment stricture of the cervical oesophagus (short arrow) with proximal dilatation and intraluminal filling defect (long arrow).

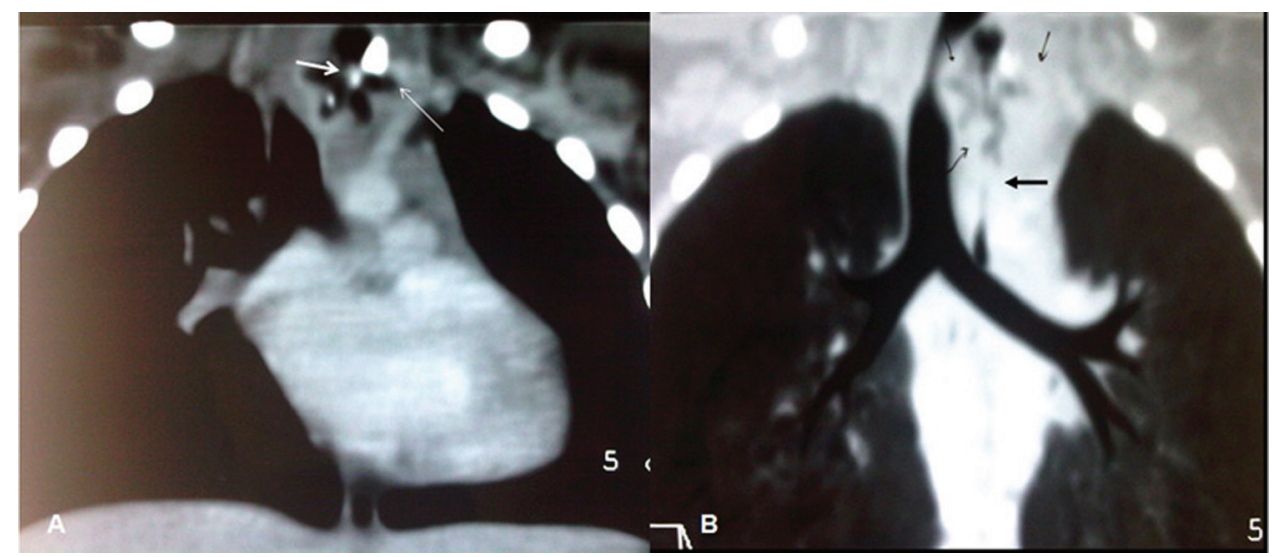

Figure 2 (A) Reconstructed coronal CT images showing flower-shaped hypodensity (white arrow) with a central hyperdense 'hole' (thick arrow). (B) Reconstructed coronal CT images showing a 'stricture' (thick arrow) distal to the outpouching (short arrows).

also be considered in infants with symptoms such as excessive drooling, refusal to feed, unexplained gagging or chronic aspiration, especially if sudden in onset. The predominant presenting symptom in our child was vomiting and refusal to take solids. True non-food foreign body ingestions are more common in children, the majority of whom are aged 6 months to 6 years, ${ }^{3}$ as was the case in our patient.

For patients who ingest foreign bodies, preoperative radiography is an invaluable tool that allows the clinician 


\section{BMJ Case Reports}

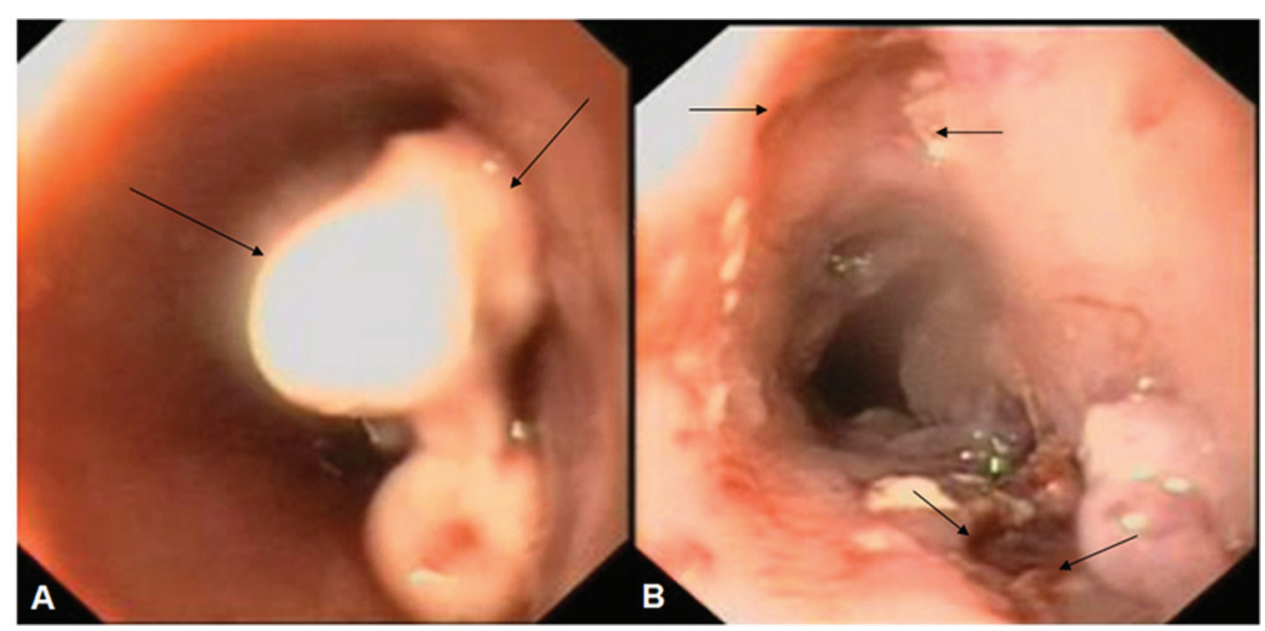

Figure 3 (A) Endoscopic image of flower-shaped impacted foreign body seen from above (arrows). (B) Endoscopic image of upper oesophagus showing deep ulcers (arrows) at the site of foreign body impaction.

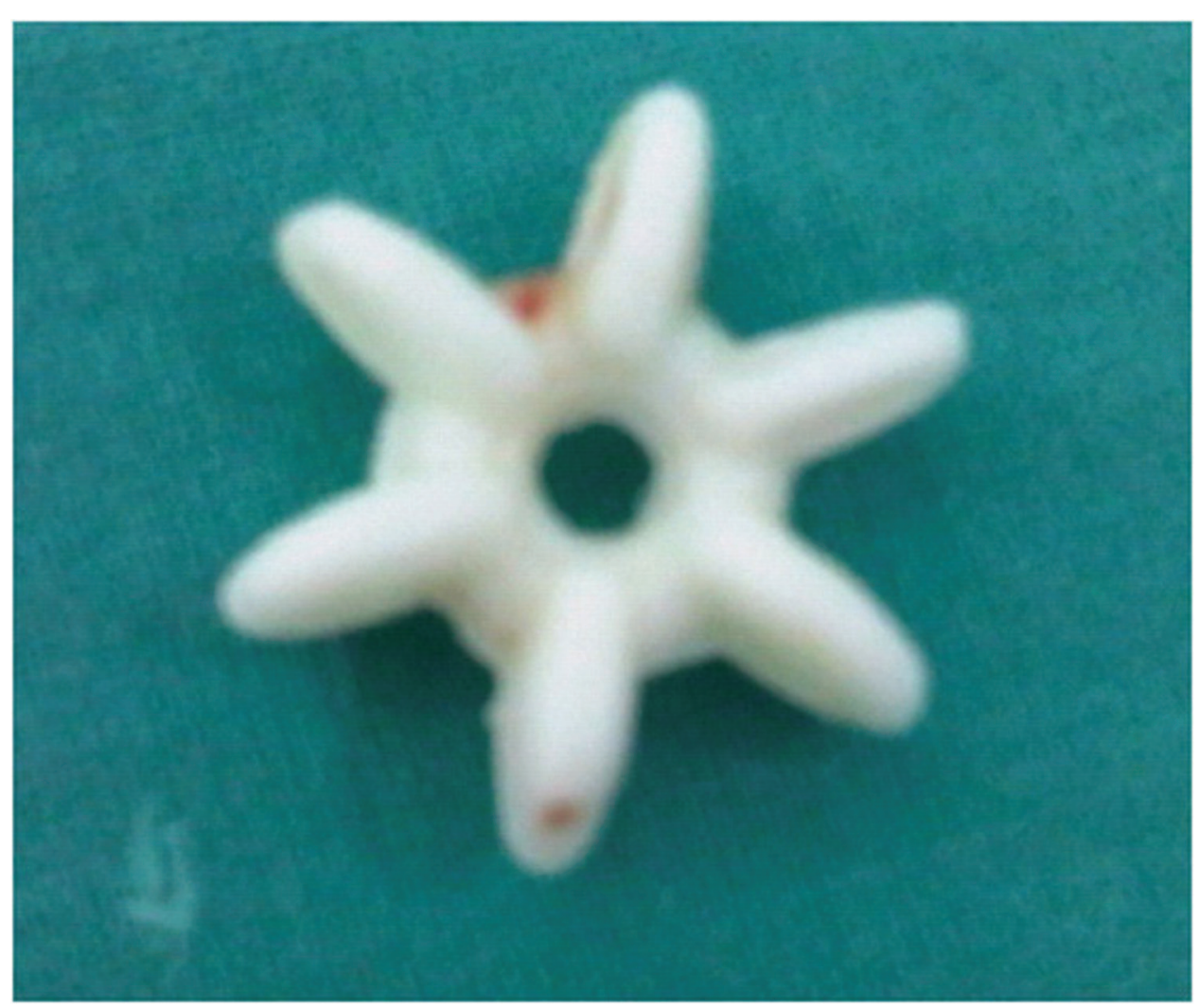

Figure 4 Extracted flower-shaped hard plastic foreign body with a central hole.

to confirm the presence of the foreign body, pre-empt potential difficulties and plan the best method for foreign body removal as well as identify potential pitfalls. The problem arises when the history is not clear, and the foreign object is unusual, impacted but partially obstructing and non-radio-opaque. In infants and small children, we expect history from neither the child nor the mother. Also the clinical presentation of foreign body impaction will vary greatly depending upon the degree of lumen compromise, making it all the more important to have a high degree of suspicion.
The choice of radiological examination is generally determined by the site of symptom - plain lateral neck x-rays for throat discomfort localised above the sternum and barium swallow for those that are retrosternal in nature. The information obtained from radiography can often confirm the presence or absence of a foreign body and provide vital data about the foreign body with regard to its site, shape and size. ${ }^{4}$ This information is vital as inadvertent breakage of foreign bodies sometimes occurs during removal and a second look may be mandated when the extradited foreign body is smaller than the one expected from radiological 


\section{BMJ Case Reports}

examination. The choice of radiological investigation is difficult in infants in view of poor localisation of symptoms and signs.

Barium swallow on fluoroscopy can outline radiolucent foreign body with signs of intraluminal obstruction and gives us the great benefit of being a dynamic realtime examination. CT should be kept as the last resort when all other modalities fail to demonstrate the obstructive pathology or when extraluminal pathology is being considered.

The key principles in endoscopic management of oesophageal foreign bodies are to protect the airway, maintain control of the object during extraction and avoid causing additional damage. ${ }^{5}$

In our patient, in retrospect, the barium swallow (figure 1) showed a filling defect in the proximal dilated segment strongly hinting towards the presence of a foreign body, since the patient had not accepted solid feeds for weeks before the examination. The 'stricture' in the oesophagus was probably reported due to the narrowed lumen secondary to the presence of the foreign body. A reconstructed coronal section of CT scan very clearly showed a hypodense flower-shaped 'outpouching' in the cervical oesophagus that was indeed nothing but the impacted foreign body with the central hyperdensity, which was the central hole in the foreign body (figure $2 \mathrm{~A}$ ).

\section{Learnimg points}

- The possibility of foreign body ingestion should be considered for unexplained, sudden onset upper gastrointestinal symptoms such as vomiting in a child.

- A high index of suspicion for a foreign body should be maintained in interpreting unexplainable radiological findings.

\section{Competing interests None.}

Patient consent Obtained.

\section{REFERENCES}

1. Byard RW. Mechanisms of unexpected death in infants and young children following foreign body ingestion. J Forensic Sci 1996;41:438-41.

2. Duncan M, Wong RK. Esophageal emergencies: things that will wake you from a sound sleep. Gastroenterol Clin North Am 2003;32:1035-52.

3. Cheng W, Tam PK. Foreign-body ingestion in children: experience with 1,265 cases. J Pediatr Surg 1999;34:1472-6.

4. Haglund S, Haverling M, Kuylenstierna R, et al. Radiographic diagnosis of foreign bodies in the oesophagus. J Laryngol Otol 1978;92:1117-25.

5. Smith MT, Wong RK. Esophageal foreign bodies: types and techniques for removal. Curr Treat Options Gastroenterol 2006;9:75-84

This pdf has been created automatically from the final edited text and images.

Copyright 2011 BMJ Publishing Group. All rights reserved. For permission to reuse any of this content visit

http://group.bmj.com/group/rights-licensing/permissions.

BMJ Case Report Fellows may re-use this article for personal use and teaching without any further permission.

Please cite this article as follows (you will need to access the article online to obtain the date of publication).

Mahajan M, Gandhi V, Nagral A. An unusual cause of vomiting in a child. BMJ Case Reports 2011;10.1136/bcr.02.2010.2745, date of publication

Become a Fellow of BMJ Case Reports today and you can:

- Submit as many cases as you like

- Enjoy fast sympathetic peer review and rapid publication of accepted articles

- Access all the published articles

- Re-use any of the published material for personal use and teaching without further permission

For information on Institutional Fellowships contact consortiasales@bmjgroup.com

Visit casereports.bmj.com for more articles like this and to become a Fellow 